\title{
First report of Rhodnius montenegrensis (Hemiptera: Reduviidae: Triatominae) infection by Trypanosoma rangeli
}

\author{
Dionatas Ulises de Oliveira Meneguetti ${ }^{[1]}$, Evanildo Bezerra Soares ${ }^{[2]}$, \\ Marta Campaner ${ }^{[3]}$ and Luis Marcelo Aranha Camargo ${ }^{[4],[5]}$
}

[1]. Programa de Pós Graduação em Biologia Experimental, Fundação Universidade Federal de Rondônia, Porto Velho, RO. [2]. Departamento de Saúde, Faculdade de Educação e Meio Ambiente, Ariquemes, RO. [3]. Departamento de Parasitologia, Instituto de Ciências Biomédicas, Universidade de São Paulo, São Paulo, SP. [4]. Instituto de Ciências Biomédicas, Universidade de São Paulo, Monte Negro, RO. [5]. Departamento de Medicina, Faculdade São Lucas, Porto Velho, RO.

\begin{abstract}
Introduction: This study reports for the first time the infection of Rhodnius montenegrensis by Trypanosoma rangeli. Methods: The triatomines were manually collected in Attalea speciosa in the municipality of Buritis, Rondônia. The identification of the trypanosomatid species was confirmed by multiplex PCR. Results: All of the collected triatomines were R. montenegrensis. The analysis confirmed that all of the adults were infected with the epimastigote form of T. rangeli. Conclusions: This report of a new vector of $T$. rangeli raises a warning for the State of Rondônia because the simultaneous presence of $T$. rangeli with $T$. cruzi in the same geographic region enables the occurrence of mixed infections in hosts and vectors, which complicates the differential diagnosis.
\end{abstract}

Keywords: Triatominae. Trypanosoma rangeli. Rhodnius montenegrensis. Western Amazon.

Trypanosoma rangeli is a heterogeneous hemoflagellate protozoan discovered in Venezuela in the intestinal contents of Rhodnius prolixus and, in addition to Trypanosoma cruzi, is the only trypanosome parasite of man found in Central and South America ${ }^{1}$.

Trypanosoma rangeli has been reported in Colombia, Mexico, Guatemala, Honduras, El Salvador, Nicaragua, Costa Rica, Panama, Guyana, Fr Guyana, Uruguay, Paraguay, Peru, Chile, Venezuela, Trinity, Argentina, Ecuador, Bolivia and Brazil ${ }^{2,3}$. In Brazil, it was found in wild animals and triatomines in the south (Santa Catarina), southeast (Minas Gerais), northeast (Ceará, Alagoas and Bahia), central west (Federal District, Goiás, Mato Grosso and Mato Grosso do Sul) and north (Amazonas, Pará, Rondônia, Acre and Tocantins) regions ${ }^{2,4,5}$.

From the earliest reports of human infection by $T$. rangeli in the Americas, more than 2,700 cases of human rangeliosis have been confirmed ${ }^{6}$. The only cases of human infection reported in Brazil have been in the States of Amazonas and Bahia ${ }^{7,8}$, but in contrast to T. cruzi, T. rangeli is not considered pathogenic to its vertebrate hosts ${ }^{3}$.

The transmission of $T$. rangeli to vertebrates is mainly related to species of triatomines of the genus Rhodnius, with 12 species reported as their natural vectors; of these 12 species, 6 are found

Address to: Dr. Dionatas Ulises de Oliveira Meneguetti. PPGBIOEXP/UNIR Campus-BR 364, Km 9.5, 76801-059 Porto Velho, RO, Brasil.

Phone: 5569 9243-7860

e-mail: dionatas@icbusp.org

Received 7 September 2013

Accepted 27 November 2013 in Brazil (Rhodnius neglectus, Rhodnius nasutus, Rhodnius neivai, Rhodnius domesticus, Rhodnius pictipes and Rhodnius robustus $)^{2,9,10}$. The latter species may have been erroneously described in the State of Rondônia by some researchers ${ }^{11,12}$ because of its similarity to $R$. montenegrensis, which had not been described at that time.

Rhodnius montenegrensis was first described in 2012 from specimens collected in the municipality of Monte Negro, Rondônia, Brazil. Initially, it was identified as $R$. robustus, but subsequent studies showed that it was a new species ${ }^{13}$.

The present study reports the first documented infection of Rhodnius montenegrensis (Hemiptera: Reduviidae: Triatominae) by Trypanosoma rangeli.

Monthly collections were performed with permission from the Brazilian Institute of Environment and Renewable Natural Resources (Instituto Brasileiro do Meio Ambiente e dos Recursos Naturais Renováveis - IBAMA), permanent license No. 14934-1 from June to December of 2012 in the rural pasture area in the municipality of Buritis, Rondônia (Latitude

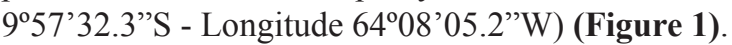

Triatomines were collected from 14 specimens of Attalea speciosa (babassu) twice a month in the morning after downing a tree with a chainsaw and removing the bracts. Triatomines were manually collected through active searching. The $A$. speciosa were randomly selected, drawing any 1 from a group of 20 .

The collected specimens were sent in a cooler at room temperature to the microscopy laboratory at the School of Education and Environment (Faculdade de Educação e Meio Ambiente - FAEMA) in the municipality of Ariquemes, Rondônia, where wet mount analysis and smear analysis of 


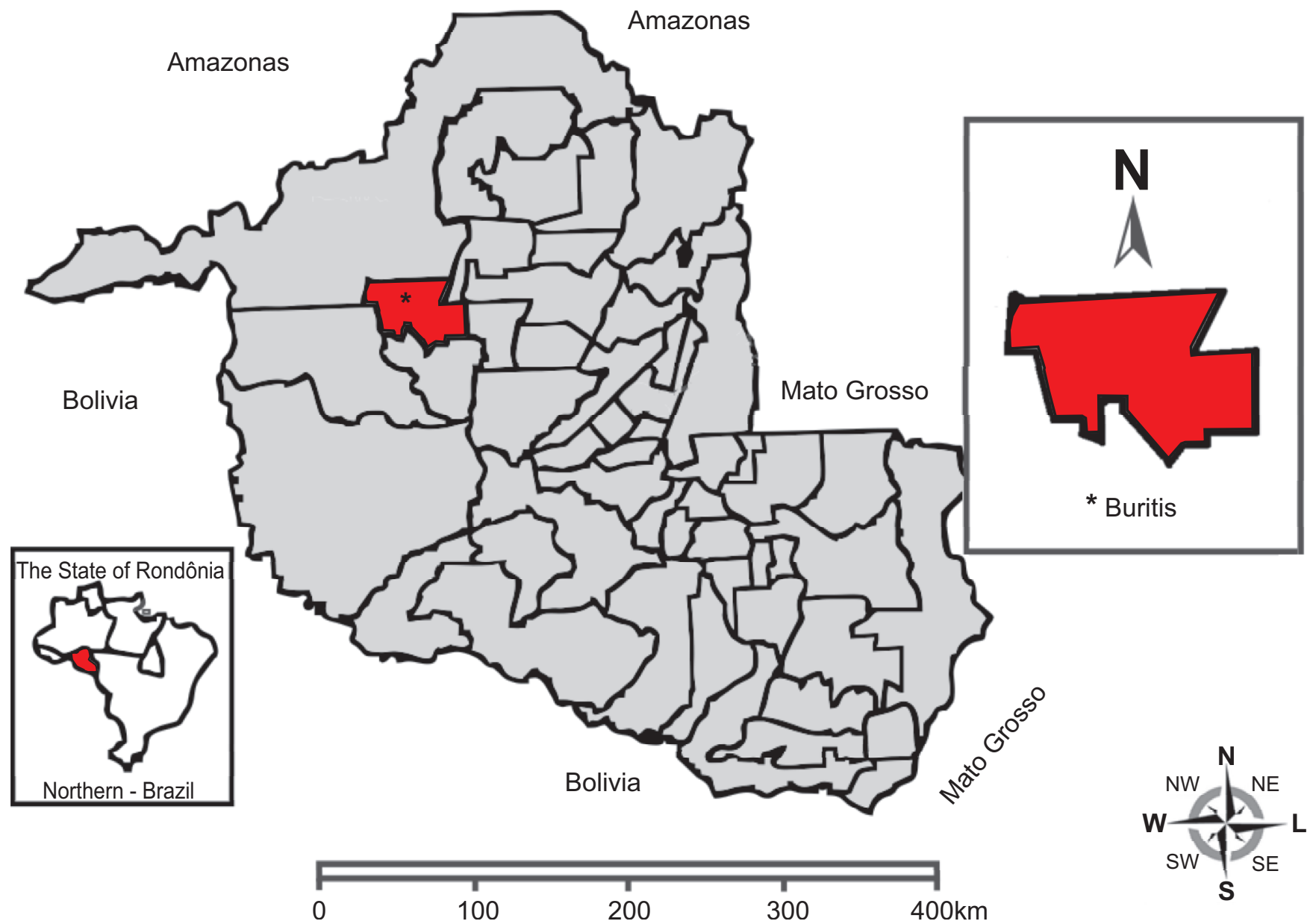

FIGURE 1 - Geographical location of the municipality of Buritis, State of Rondônia, Brazil.

the adult triatomines' rectal contents were performed with an optical microscope at $1600 \mathrm{X}$ magnification after staining with triarylmethane $(0.1 \%)$, xanthene $(0.1 \%)$ and thiazine $(0.1 \%)$ (Figure 2).

The identification of the trypanosomatid species was confirmed by multiplex polymerase chain reaction (PCR) in collaboration with the Department of Parasitology at the Institute of Biomedical Sciences, São Paulo University (ICB-USP), São Paulo (SP), Brazil.

Parasite deoxyribonucleic acid (DNA) was extracted from the triatomine rectal samples using a Qiagen DNA extraction kit. The multiplex PCR was performed according to Fernandes et al. ${ }^{14}$. This method amplifies a portion of the non-transcribed spacer of the mini-exon gene that varies between $T$. cruzi and $T$. rangeli species and between lines 1 and 2 of $T$. cruzi. The following primers were used: TC1, 5'-ACACTTTCTGGCGCTGATCG-3'; TC2, 250bp, 5'-TTGCTCGCACACTCGGCTGCAT-3'; Z3, 150bp, 5'-CCGCGCACAACCCCTATAAAAATG-3'; TR, 100bp, 5'-CCTATTGTGATCCCCATCTTCG-3' and EXON, 5'-TACCAATATAGTACAGAACTG-3'. The reaction mixture consisted of $100 \mathrm{pmol}$ of each primer and $150 \mu \mathrm{M}$ dNTPs in a buffer composed of $10 \mathrm{mM}$ Tris- $\mathrm{HCl}(\mathrm{pH} 8.3), 1.5 \mathrm{mM} \mathrm{MgCl}_{2}$,
$25 \mathrm{mM} \mathrm{KCl}, 0.1 \mathrm{mg} / \mathrm{ml}$ bovine serum albumin, $2.5 \mathrm{U}$ of Taq DNA polymerase and 10ng of genomic DNA in a total volume of $50 \mu \mathrm{L}$. The thermal cycling conditions were as follows: an initial step of $5 \mathrm{~min}$ at $95^{\circ} \mathrm{C}, 34$ cycles of $30 \mathrm{sec}$ at $94^{\circ} \mathrm{C}$, $30 \mathrm{sec}$ at $55^{\circ} \mathrm{C}$ and $30 \mathrm{sec}$ at $72^{\circ} \mathrm{C}$ and a final extension of $10 \mathrm{~min}$ at $72^{\circ} \mathrm{C}$. The following reference strains were used as controls in each reaction: TC1, X10 Clone 1; TC2, Strain Y; Z3, Emerald Clone 1 and T. rangeli R1625. The amplified products were subjected to electrophoresis on a $2 \%$ agarose gel at $100 \mathrm{~V}$ for $1 \mathrm{~h}$. After electrophoresis, the DNA was stained with ethidium bromide and visualized under ultraviolet light. A molecular marker of 50 base pairs was used as a size control for the amplified fragments.

The identification of the adult triatomine species was conducted based on the keys previously described by and Rosa et al. ${ }^{12}$.

A total of 120 triatomines were collected, providing an average of 8.6 specimens per Attalea speciosa, which is below the average reported by other studies in the state ${ }^{9,11}$. Of those triatomines, only $13(10.8 \%)$ were adults, and all were $R$. montenegrensis.

The analysis confirmed that all of the adults were infected with trypanosomatids, with the T. rangeli in the epimastigote form. 


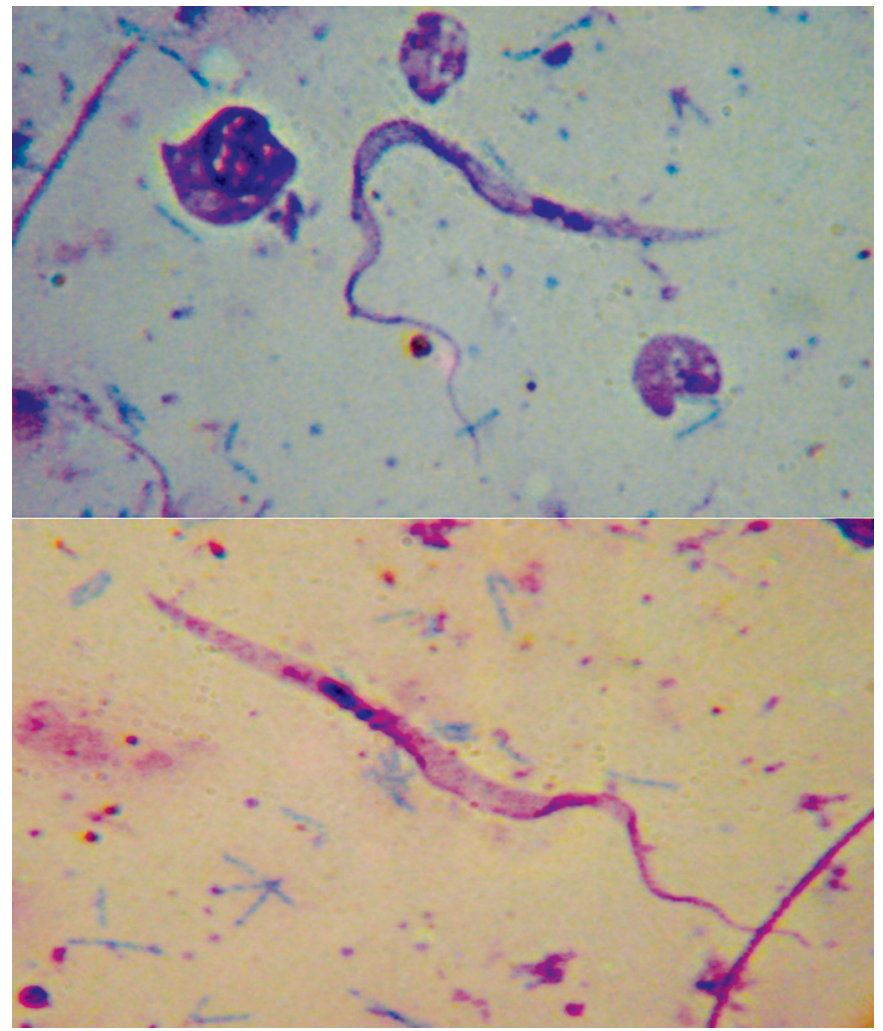

FIGURE 2 - Epimastigote form of Trypanosoma rangeli at 1600X magnification.

This work is the first report of the infection of $R$. montenegrensis by $T$. rangeli, which increases the total number of species of triatomines of the genus Rhodnius infected by this protozoan to 13, including 7 species found specifically in Brazil.

This report of a new vector of $T$. rangeli presents a warning to the State of Rondônia because the simultaneous presence of T. rangeli and $T$. cruzi in the same geographic region enables the occurrence of mixed infections in both vertebrate hosts and vectors, which complicates the differential diagnosis of an infection ${ }^{15}$. This possibility is concerning, especially in a state where there are reports of other vector species of $T$. rangeli, such as R. pictipes and R. robustus ${ }^{11,12}$.

\section{CONFLICT OF INTEREST}

The authors declare that there is no conflict of interest.

\section{REFERENCES}

1. Ramirez LE, Machado MI, Maywald PG, Matos A, Chiari E, Silva EL. Primeira evidência de Trypanosoma rangeli no sudeste do Brasil, região endêmica para doença de Chagas. Rev Soc Bras Med Trop 1998; 31:99-102.

2. Vargas PAO. Genes de Cisteíno Proteases (Catepsina L-like) de Trypanosoma rangeli: Polimorfismo, Relações Filogenéticas e Alvos Para Diagnóstico e Genotipagem. [Dissertation]. [São Paulo]: Instituto de Ciências Biomédicas da Universidade de São Paulo; São Paulo, 2008.

3. Guhl F, Vallejo GA. Trypanosoma (Herpetosoma) rangeli Tejera, 1920: an updated review. Mem Inst Oswaldo Cruz 2003; 98:435-442.

4. Gurgel-Gonçalves R, Cura C, Schijman AG, Cuba CAC. Infestation of Mauritia flexuosa palms by triatomines (Hemiptera: Reduviidae), vectors of Trypanosoma cruzi and Trypanosoma rangeli in the Brazilian savanna. Acta Trop 2012; 121:105-111.

5. Diotaiuti I, Silveira AC, Elias M, Steindel M. The possibility of occurrence of Trypanosoma rangeli in the State of Tocantins, Brazil. Mem Inst Oswaldo Cruz 1992; 87:451.

6. Grisard EC, Steindel M. Trypanosoma (Herpetossoma) rangeli. In: Neves PN, Melo AL, Linarde PM, Vitor RWA, editors. Parasitologia Humana. Vol XI. São Paulo: Atheneu 2005; p. 109-113.

7. Coura JR, Fernandes O, Arboleda M, Barrett TV, Carrada N, Degrave W, et al. Human Infection by Trypanosoma rangeli in the Brazilian Amazon. Trans R Soc Trop Med Hyg 1996; 90:278-279.

8. Sousa MA, Silva Fonseca T, Santos BN, Santos Pereira SM, Carvalhal C, Hasslocher Moreno AM. Trypanosoma rangeli Tejera, 1920, in chronic Chagas disease patients underambulatory care at the Evandro Chagas Clinical Research Institute (IPEC-FIOCRUZ, Brazil). Parasitol Res 2008; 103:697-703.

9. Gurgel-Gonçalves R, Galvão C, Costa J, Peterson AT. Geographic distribution of Chagas disease vectors in Brazil based on ecological niche modeling. J Trop Med 2012: 1-15.

10. Barrett TV, Oliveira TS. A trypanosome, indistinguishable from Trypanosoma rangeli, in the haemolymph of Rhodnius domesticus from Brazil. Trans $\mathrm{R}$ Soc Trop Med Hyg 1977; 71:445-446

11. Meneguetti DUO, Trevisan O, Rosa RM, Camargo LMA. First report of Eratyrus mucronatus, Stal, 1859, (Hemiptera, Reduviidae, Triatominae) in the State of Rondonia, Brazil. Rev Soc Bra Med Trop 2011; 44:511-512

12. Meneguetti DUO, Trevisan O, Camargo LMA, Rosa RM. Natural infection of triatomines (Hemiptera: Reduviidae) by trypanosomatids in two different environments in the municipality of Ouro Preto do Oeste - Rondônia, Brazil. Rev Soc Bra Med Trop 2012; 45:395-398.

13. Rosa JA, Rocha CS, Sueli G, Mara CP, Vagner JM, Júlio CRFF, et al. Description of Rhodnius montenegrensis n. sp. (Hemiptera: Reduviidae: Triatominae) from the state of Rondônia, Brazil. Zootaxa 2012; 3478:62-76.

14. Fernandes O, Santos SS, Cupolillo E, Mendonça B, Derre R, Junqueira ACV, et al. A mini-exon multiplex polymerase chain reaction to distinguish the major groups of Trypanosoma cruzi and Trypanosoma rangeli in the Brazilian Amazon. Trans R Soc Trop Med Hyg 2001; 95:97-99.

15. Miles MA, Arias JR, Valente SAS, Naiff RD, Souza AA, Povoa MM, et al. Vertebrate hosts and vetors of Trypanosoma rangeli in the Amazon basin of Brazil. Am J Trop Med Hyg 1983; 32:1251-1259. 